\title{
The H1N1 vaccine race: Can we beat the pandemic?
}

$\mathrm{C}$ anada proudly claims to be the first nation with an influenza pandemic plan - a response, in part, to the lack of vaccine during the 1976 swine flu scare. We are told that there is a guaranteed supply of pandemic vaccine from a domestic source. ${ }^{1}$ But this is only the first step.

The bigger issue is: Will we be able to immunize vulnerable populations in time?

Under the current plan, the answer is "No." Vaccines must pass a regulatory process for licensing, and Health Canada, the licensing authority, has decided to treat this virus like a new subtype rather than a variant $\mathrm{H} 1 \mathrm{~N} 1$ strain, requiring a more extensive review and a slower rollout. But consider these facts:

- The immunizing antigens of the pandemic (H1N1) 2009 virus are closely related to those of modern "swine flu" viruses. They are also related to a series of human viruses from 1918-1956.

- Exposure to older influenza viruses primes people to resist related viruses. In clinical trials in 1976, people born before about 1957 responded well to a single dose of swine flu vaccine, without adjuvant. ${ }^{2,3}$ Consistent with this effect, people born before about 1957 have been largely protected against the new pandemic virus. ${ }^{4}$ Thus, most adults over 50 are "primed" to the 2009 virus, even though antibodies to the new variant often cannot be found in their blood with current tests. $^{5}$

- H1N1 viruses reappeared in 1977 and caused major outbreaks mainly in those aged 25 or younger over the following few years. ${ }^{6}$ People in that birth cohort are now about 25 to 50 years old. It is no surprise, then, that illnesses from the new pandemic (H1N1) 2009 virus have peaked among adolescents and children, who have had the least exposure to seasonal H1N1 strains.

- The current outbreak has not affected broad sectors of the population to date. In fact, the severe acute lung injuries caused by the pandemic (H1N1) 2009 strain have been mainly in adults (most often in First Nations people, those with various chronic medical conditions and women late in pregnancy). Younger children have been admitted to hospital at higher rates, too, as occurs during most influenza epidemics. ${ }^{7}$

A vaccine is needed for a variety of high-risk individuals, and the earlier it is used, the greater the chance to protect them before the epidemic season peaks. This will reduce the burden on hospitals and scarce intensive care spaces.

With stocks of vaccine antigen rapidly building, licensing authorities face two choices. The first is to review and license both the vaccine and adjuvant as a package. Alternatively, they can fasttrack the vaccine review and conduct an expedited slower review for the vaccine and adjuvant. Each choice has consequences:

- The use of the standard vaccine without an adjuvant can be fast-tracked to high-risk groups, as with any seasonal update. However, there may not be enough vaccine for the general public.

- The use of an adjuvant requires a more thorough and slower review process, even when expedited. Therefore, vaccinations cannot begin as quickly, but more people would be immunized. Other countries, such as Australia, members of the European Union and the United States, plan to license their 2009 pandemic vaccine by the faster path. Some, in fact, are choosing both: fast-track licensing for use in high-risk groups and the slower process for the rest of the population.

Health Canada has chosen the slower path. That might be reasonable if the vaccine without adjuvant fails to be effective. But what if ongoing clinical results show good performance of the fast-track vaccine? Can the fast-track approach be used to license such a product quickly? At present, in Canada, the answer is "No." We are not suggesting that we sacrifice safety. But we must be able to readjust our plans quickly, depending on results of the soon-to-be completed trials.

Having enough vaccine for every Canadian would make more sense if the pandemic virus were highly virulent for large proportions of the population. But given current evidence, it seems a poorer choice than providing coverage to high-risk groups as early as possible.

Time is running out. Only by providing fast-track standard vaccine might high-risk groups be protected in a timely way, while the general public awaits the arrival of the adjuvant vaccine. Without an immediate change in policy, high-risk groups in Canada will be waiting for protection, while their US and European counterparts are vaccinated. Health professionals must have access to standard vaccines by early October and to adjuvant vaccine no later than midNovember to protect the public.

Health Canada seems to have forgotten that while being first with a plan is good, being fast to vaccinate will save lives.

\section{Paul C. Hébert MD MHSc}

Editor-in-Chief

Noni MacDonald MD MSc

Section Editor, Public Health

CMAJ

Editorial advisory team: Ken Flegel MDCM MSc

and Joan Ramsay BA

Competing interests: See www.cmaj.ca/misc/edboard.shtml

Cite as CMAJ 2009. DOI:10.1503/cmaj.091560

\section{REFERENCES}

1. Public Health Agency of Canada. Vaccine development process. Ottawa (ON): The Agency; 2009. Available: www.phac-aspc.gc.ca/alert-alerte/h1n1/h1n1bck-eng.php (accessed 2009 Aug. 27)

2. Parkman PD, Hopps HE, Rastogi SC, et al. Summary of clinical trials of influenza virus vaccines in adults. J Infect Dis 1977;136:S722-30.

3. US Centers for Disease Control. Recommendation of the Public Health Service Advisory Committee on Immunization Practice: Influenza vaccine - supplemental statement. MMWR 1976;25:221-7.

4. World Health Organization. New influenza A (H1N1) virus: global epidemiological situation, June 2009. Wkly Epid Rec 2009;84:249-60.

5. US Centers for Disease Control and Prevention. Serum cross-reactive antibody response to a novel influenza A $(\mathrm{H} 1 \mathrm{~N} 1)$ virus after vaccination with seasonal influenza vaccine. MMWR 2009;58:521-4.

6. US Centers for Disease Control. Laboratory-based surveillance of influenza United States, worldwide. MMWR 1979;28:166-7.

7. Australia Government Department of Health and Ageing. Australian influenza report 2009 - 18 to 24 July 2009. Canberra (Australia): The Department; 2009. Available: www.health.gov.au/internet/main/publishing.nsf/Content/cda-ozflu-24-7 -09.htm (accessed 2009 Aug. 27). 